\title{
AN EXPERIMENTAL STUDY OF EJECTED FLAMES AND COMBUSTION EFFICIENCY
}

\author{
Tokiyoshi YAMADA, Ken-ichi TAKANASHI, Eiji YANAI \\ Takeshi SUZUKI and Ai SEKIZAWA \\ National Research Institute of Fire and Disaster \\ Mitaka, Tokyo 181-8633, JAPAN \\ Hiroomi SATOH, Hitoshi KURIOKA \\ Kajima Technical Research Institute \\ Chofu, Tokyo 182-0036, JAPAN
}

\begin{abstract}
This paper describes a series of fire experiments in a $0.9 \mathrm{~m}$ by $0.6 \mathrm{~m}$ by $0.4 \mathrm{~m}$ high compartment. A single rectangular opening is set for the ventilation with opening factors $\left(\mathrm{AH}^{0.5}\right)$ ranging from $0.02 \mathrm{~m}^{5 / 2}$ to $0.10 \mathrm{~m}^{5 / 2}$. Propane gas and three kinds of solid fuel (wood crib, PMMA and polyurethane flexible foam) are used as fuels. Mass loss rates are measured and net heat release rates are estimated with a furniture calorimeter to examine combustion efficiency, which effects ejected flame formation. Results indicate that the combustion efficiency of gas fuel depends on 'fuel to air' global equivalence ratios $(\Phi)$ and the efficiency starts to decrease at about the 0.75 of $\Phi$. Moreover, the efficiency reaches $77 \%$ when $\Phi$ is at 1.27. However, when more fuel is supplied, the efficiency is improved to 100 $\%$ at the 2.0 point, because combustion is promoted within externally ejected flames. In the case of solid fuels, maximum heat release rates become 1.5 to 2.5 times higher than the suppositional maximum heat release rate determined by the opening factor. Under these cases, flames are ejected longer and the efficiency of the combustion also recovers as well as gas fuel combustion.
\end{abstract}

KEYWORDS: ejected flame, combustion efficiency, compartment fire, equivalence ratio

\section{INTRODUCTION}

Most of recent buildings are compartmentalized by fireproof walls and/or doors, and fire propagation from one floor to upper floors through the inside of buildings is well-prevented. However, there are not so many options in countermeasures for preventing fire propagation from external openings. It is ideal but not realistic to keep enough spandrel space between the openings of each floor. Installing a horizontal cantilever plate like a balcony is one of a few effective countermeasures. Recent statistics in Japan indicate that the fire propagation from exterior windows is relatively increasing, therefore rational countermeasures are needed. A series of experiments have been conducted for establishing useful fire safety design methodology including balcony effects on propagation prevention and a part of the work was reported. [1]

When fires spread from external openings to upper floors in a building, convective and/or radiant heat flux from ejected flames to combustibles on upper floors is especially considered to be an important factor. In particular, radiant heat from the ejected flames enables 
fire spread beyond glass. Characteristics of flames from pool fires are studied thoroughly, and engineering prediction models have been established. However, ejected flame configurations are not well understood and neither is the mechanism of the ejected flame formation. Some empirical models are proposed by Thomas et al.[2], Jansson et al. [3] and experimental research is conducted by other researchers [4][5][6]. However, those models were not utilized as consentaneous engineering models to predict fire propagation from the ejected flames.

For establishing ejected flame models, we have collected flame configuration data by reduced-scale model experiments under various conditions using a VCR image-data.[7] Luminous flames are extracted and time-averaged by processing the images: i.e., the luminous flame is supposed to satisfy the condition, i) $r_{i j}>120$ and $b_{i j}<200$ in addition ii) $r_{i j}$ $>b_{i j}$ in the case of $120<r_{i j}<200$. Where $\left(r_{i j}, g_{i j}, b_{i j}\right)$ is the color index value of RGB (ranging from 0 to 255 ) in each pixel at position $(i, j)$. Through observing the experiments, it is considered to be important to comprehend the heat release rate contributing to ejected flame formation, especially combustion phenomena including combustion efficiency, for the modeling. The heat release rate of the scale-model compartment fires is measured with a furniture calorimeter. This paper describes the relation between combustion efficiency $(\eta)$ and a net global equivalence ratio characterized by the supplied fuel and the maximum heat release rate $\left(Q_{\text {vmax }}\right)$ determined by the opening factor $\left(A H^{0.5}\right)$, and it examines the influence on ejected flames along with the results by observations.

\section{Review}

Both models of Thomas et al.[2] and Jansson et al.[3] are derived from experimental data of mass loss rates in post flashover. The key issue is to estimate how much the heat release rate can contribute to flame formation. As for the ejected flame lengths in the case without balconies, the former model gives the following experimental equation based on many experimental studies using wooden cribs. [2]

$$
H+Y=18.6\left(m_{\text {wood }} / B\right)^{2 / 3} \text {----------(Eq.1) }
$$

where $H, B$ : height and width of the ventilation opening respectively (m)

$Y \quad$ : height of flame tip above opening soffit (m)

$m_{\text {wood }}$ : rate of burning of wooden cribs $(\mathrm{kg} / \mathrm{s})$

This empirical equation can be theoretically explained by ventilation driven flames as shown in Fig.1(a). In other words, flames are ejected in proportion to ventilation efflux as if the efflux establishes flames. This means that ejected flames mainly depend on room temperature that determines equilibrium of both burning rate and air supply. Similar models are often used in Japan, i.e., an imaginary line fire source is supposed to exist at a neutral zone position and the heat release rate is given as total heat of hot vent from openings. This conventional model is simple and practical, however ejected flames are supposed to appear even if the total amount of heat release rate is relatively small, which dose not fit the reality.

The Jansson-Onnermark model [3] seems to be a more refined model for considering combustion phenomena. Ejected flames are established by unburnt fuel discharged from a fire compartment as shown in Fig .1(b). The model defines a lower limit of critical burning rate $\left(m_{v c r i t}\right)$ inside the compartment as a function of the opening factor $\left(A H^{0.5}\right)$ as shown in Fig. 2. The variance between the maximum burning rate $\left(m_{v \max }\right)$ determined by $5.5 A H^{0.5}(\mathrm{~kg} /$ 
Burning rate is controlled by

vent which depends on

room temperature.

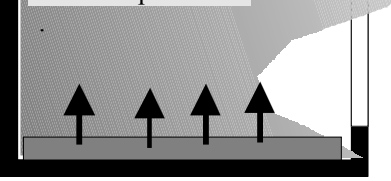

(a) Ventilation controlled model a) Flame ejects as if it is induced by hot efflux.

b) Surplus unburnt fuel burns outside and establishes flame.
Burning rate is controlled

by thermal condition inside and property of fue.1

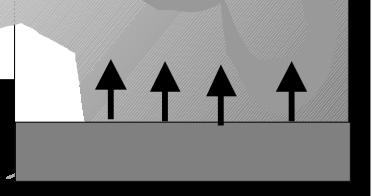

Fig. 1 - Schema of models of flames ejected from fire compartment

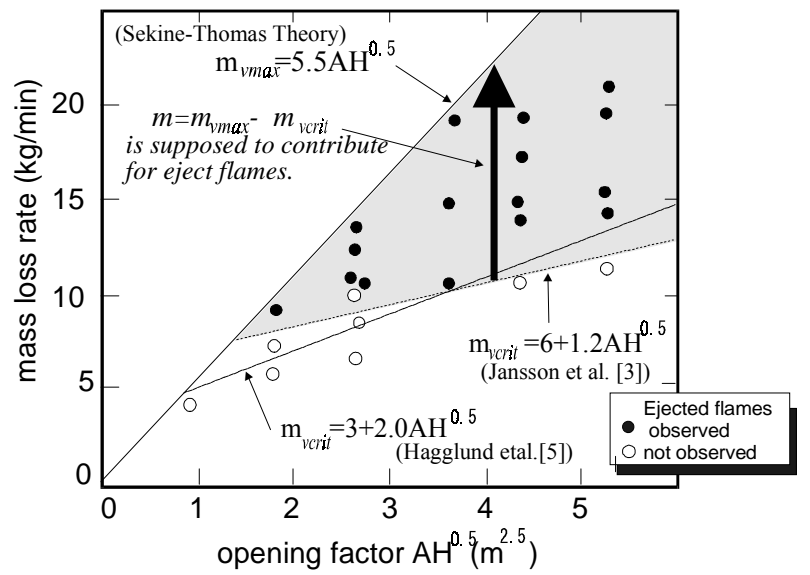

Fig. 2 - Existing models of ejected flames based on unburnt fuel combustion-hypothesis: [3][5]

min) and the critical burning rate is supposed to be the unburnt fuel, which contributes to ejected flame formation. Hägglund [5] proposed a similar model prior to the above model in a slightly different manner, and the variance region was characterized as a flashover region. This concept of the model is easy to understand intuitively, however some questions remain, i.e., whether the critical value depends on the configuration of room and will surplus unburnt gas be completely burnt outside of the building or not, because Hasemi [4] indicated that the estimated flame height was almost half of that in open air and a similar tendency was reported by Bøhm [8]

Both models suppose that ejected flames depend on the maximum mass loss rate characterized by the opening factor. However a fundamental difference is that the model(b) attaches more importance to combustion process than to ventilation efflux as the model (a) dose.

It is not our immediate objective at the moment to decide which model is more reasonable for explaining the phenomena, because the real phenomena seems to be a mixture of both mechanisms. However, one of our intentions is to find how the mass loss rate can be converted into the heat release rate that seems to be dominant factor to determine the flame configuration. Moreover, whether the maximum mass loss rate described by the conventional expression $5.5 \mathrm{AH}^{0.5}(\mathrm{~kg} / \mathrm{min})$ is adequate or not, even when the flames are burning 
outside of the compartment through openings, should be examined. This is because some pictures of real fires in articles seemed to present longer flames than the rough estimation predicted by the previous models.

A series of experiments are conducted with a reduced-scale compartment and a furniture calorimeter to figure out the maximum heat release rate and the combustion efficiency. Relations between those values and ejected flame configurations are also examined.

\section{OUTLINE OF THE EXPERIMENT}

\section{Model Configuration}

A series of experiments are conducted with a $1 / 7$-scale model positioned in the furniture calorimeter, as shown in Fig. 3, which is assumed to be a part of a high-rise residential building. The height of this model is equivalent to that of three floors (one floor is $0.4 \mathrm{~m}$ in height). The inside size of the fire compartment is $0.93 \mathrm{~m}$ wide by 0.575 $\mathrm{m}$ deep by $0.375 \mathrm{~m}$ high. It is made of steel and the inside is thermally insulated with kaowool fiber of $2.5 \mathrm{~cm}$ thickness. A single rectangular opening is set at the center on the façade of the fire room. The height from the floor to the soffit of the opening is 0.3 $\mathrm{m}$ and the width can be changed from $0.1 \mathrm{~m}$ to $0.6 \mathrm{~m}$, which is in the range from $0.0164 \mathrm{~m}^{5 / 2}$ to $0.0986 \mathrm{~m}^{5 / 2}$ of the opening factor. A surface wall from one floor below to the upper floor is set up on the $45 \mathrm{~cm}$ wide face and on both sides as well. This wall is free from the fire room with a narrow gap for reducing a total weight of the fire room to be measured.

\section{Fuel}

As fuels, propane gas and three kinds of solid fuels are used respectively. Gas fuel is adopted, because it is easy to control the supply flow rate. Also the combustion efficiency and the lower limit of the critical heat release rates $\left(Q_{v c r i t}\right)$ can be measured with relatively good accuracy. In the case of propane gas, three $0.3 \mathrm{~m}$ square sand burners are located flush with the floor and at the center of the fire room as shown in Fig.3.

In the cases of solid fuels, three kinds of solid fuels, i.e., wood cribs, PMMA and polyurethane flexible foam board as shown in Tab. 1, are positioned at the location of the burners. 
Tab. 1 - List of solid fuel

\begin{tabular}{|c|c|c|c|}
\hline Exp.No. & Configuration (in $\mathrm{mm})$ & Weight & etc \\
\hline $\begin{array}{l}\text { Wood crib } \\
\text { No.1 }\end{array}$ & $\begin{array}{l}\text { Three cribs set on the floor center (hight 60x } \\
\text { width and depth 295), stick section (15x15) single } \\
\text { clearence spacing }\end{array}$ & $3,325 \mathrm{~g}$ & $\begin{array}{l}\text { Japan cedar, moisture } \\
\text { cont. } 20.6 \% \text {, Heat of } \\
\text { comb. } 14.8 \mathrm{MJ} / \mathrm{kg}^{\text {b. }}\end{array}$ \\
\hline $\begin{array}{l}\text { Wood crib } \\
\text { No.2 }\end{array}$ & $\begin{array}{l}\text { Single crib of the same as above set on the floor } \\
\text { separately }\end{array}$ & $2,068 \mathrm{~g}$ & " \\
\hline PMMA No.1 & $\begin{array}{l}3 \text { of } 2 \text { piled plates }(290 \times 290 \times d .10 \times 2) \text { set on the } \\
\text { floor separately }\end{array}$ & $998 \mathrm{~g} \times 6$ & Heat of comb. $24.9 \mathrm{MJ} / \mathrm{kg}$ \\
\hline PMMA No.2 & $\begin{array}{l}3 \text { of single plate }(290 \times 290 \times d .10) \text { set on the } \\
\text { floor separately }\end{array}$ & $998 \mathrm{~g} \times 3$ & " \\
\hline PUF $^{a}$. No.1 & $\begin{array}{l}3 \text { of } 2 \text { piled plates }(290 \times 290 \times d .50 \times 2) \text { set on the } \\
\text { floor separately }\end{array}$ & $60 \mathrm{~g} \times 6$ & Heat of comb .26.2MJ/kg \\
\hline No.2 & $\begin{array}{l}3 \text { of single plate }(290 \times 290 \times d .50) \text { set on the floor } \\
\text { separately }\end{array}$ & $60 \mathrm{~g} \times 3$ & "I \\
\hline
\end{tabular}

Notes; a. PFU : polyurethane(flexible) foam

b. averege value is obtained by the total heat relaese divided by total weight loss in the experiment.

Wood crib is used as a major solid fuel, because it is very popular fuel in full-scale fire experiments. Two types of plastic fuel are adopted for assessing the effect of fire spreading speed on the flame formation: i.e., polyurethane flexible foam for fast spreading fire and PMMA for slower one.

\section{Procedures and measurements}

In the case of propane gas fuel, a certain amount of the gas is supplied with a mass flow controller, of which resolution is $1.7 \mathrm{~cm}^{3} / \mathrm{s}$. The experimental method is to phase to increase the amount of supplied gas from $350 \mathrm{~cm}^{3} / \mathrm{s}$ to $1,330 \mathrm{~cm}^{3} / \mathrm{s}$ by every $150 \mathrm{~cm}^{3} / \mathrm{s}$ for five minutes respectively under certain conditions of the opening. A couple of thermocouples are installed inside and outside of the fire room. In each runs, room temperature becomes in quasi-steady state at about four minutes after ignition or changing the supply flow rate. Following discussions are made by using one-minute time averaged data in the quasi steady state.

In the casesof solid fuels, it is ignited with a small pilot flame. A pool fire of $5 \mathrm{~cm}$ diameter filled with $10 \mathrm{~cm}^{3}$ methanol is set at the center and bottom of the wooden cribs as an ignition heat source. Gel-fuel made of methanol of $0.1 \mathrm{~g}$ is put at the center on the upper surface of the polyurethane flexible foam, and a $2.5 \mathrm{~g}$ solid fuel made of hexa-methylene tetramine is put on PMMA in the same manner. During fire evolution, the change in the weight of the whole fire room is measured with a platform scale (resolution $=1 \mathrm{~g}$, full scale $=150 \mathrm{~kg}$ ) by every second. The data are smoothen by averaging 10 seconds prior to each time point for eliminating short term fluctuations.

In both cases, the heat release rate is measured with the furniture calorimeter during each runs in almost the same manner described in the ISO 9705 full scale room test. However an exhaust flow rate is set at about $1.5 \mathrm{~m}^{3} / \mathrm{s}$. to measure relatively low heat release rate. Oxygen depletion, $\mathrm{CO}_{2}$ and $\mathrm{CO}$ concentration are measured every 5 seconds as well as the exhaust flow rate, temperature and smoke density in the exhaust duct. Before each test runs, the furniture calorimeter is calibrated with a $30 \mathrm{~cm}$ diameter methanol pool fire by making a comparison with the heat release rate estimated by mass loss rate. Moreover, digital video cameras are set in the front and on the side respectively to capture images of the ejected flames every $1 / 30$ seconds. Theses pictures are multi-layered on PC to obtain time averaged ejected flames' configuration. 


\section{RESULTS AND DISCUSSIONS}

Opening factor and ejected flames

Figure 4 shows the ranges of ejected flames from an opening that exist under various conditions of the opening and heat release rates of gas fuel. Although the units and the magnitudes of burning rates are different from those of previous experimental studies [3,5], the same tendency is shown: i.e., a lower limit of combustion $\left(Q_{v c r i t}\right)$ exists of which the slope angle is within the range between $22 \%$ [3] to $37 \%$ [5] of the maximum heat release rate controlled by ventilation $\left(Q_{\text {vax }}\right)$. Dashed lines in Fig.4 are determined to fit a boundary of ejected/no-ejected flames' region, with the same slope angle indicated in Fig.2. No direct translation from mass burning rate to heat release rate is possible, because length scale and range of burning rates of experiments are different. Minimum $Q_{v c r i t}$ on the $Q_{v \max }$ line roughly depends on the $5 / 2$ power of the length scale of the compartment in due course.

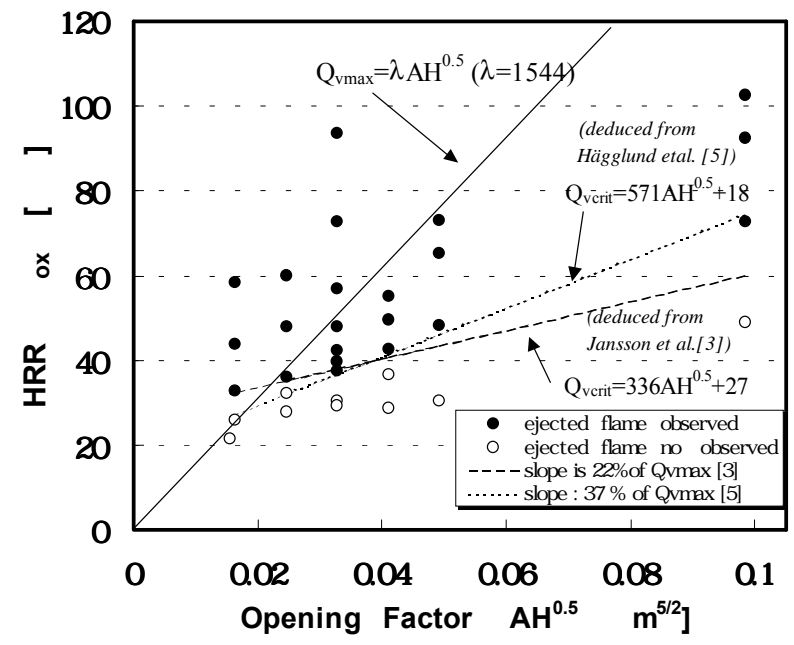

Fig. 4 - Flame ejection under different opening factor and HRR:

Plots of HRR are measured with furniture calorimeter.

Dimensional analysis was attempted by Hasemi [4]. He introduced the results that $Q_{v c r i t} /$ $A H^{0.5}$ depends more on surface area than on volume inside the compartment. This suggests that the mechanism of ejected flames is more dependent on room temperature as shown in Fig. 1(a) than the mixing combustion process, when the flames are relatively small. In this experiment no $Q_{v \max }$ information is obtained, because gas fuel is forcibly introduced into the fire room. Excessive supplied fuel continues to burn outside as longer ejected flames, and the combustion efficiency under such a condition is our objective phenomena to be examined as followings.

Opening factor and combustion efficiency in the case of gas fuel

The X-axis in Fig.5(a) indicates the nominal heat release rate $\left(Q_{\text {supl }}\right)$ of the supplied gas normalized by $Q_{v \max }$ of Eq.1, which is expressed as the 'fuel to air' net global equivalence ratio $(\Phi) . Q_{v \max }$ is the suppositional maximum heat release rate controlled by ventilation in a fully developed fire [9]. 


$$
\begin{aligned}
Q_{v \max } & =\Delta H_{\text {(air) }} m_{\text {air }} \\
& \approx 0.52 \Delta H_{\text {(air) }} A H^{0.5}=\lambda A H^{0.5}
\end{aligned}
$$

where $\Delta \mathrm{H}_{\text {(air) }}:$ heat release per amount of air ( $\mathrm{kJ} / \mathrm{kg}$ (air))

$\mathrm{A}^{(\text {air }}$ : area of the opening $\left(\mathrm{m}^{2}\right)$

$\mathrm{H} \quad$ : height from the floor to the opening soffit (m)

$\lambda$ : constant of fuel (propane gas is set to be 1544, PMMA 1565.[9] and polyurethane foam 1565 as a reference. Besides, wood cribs is 1700 , which is estimated by the following equation.

$$
Q_{\text {vmax }}=\Delta H_{(\text {wood })} m_{(\text {wood })}=18,900[\mathrm{~kJ} / \mathrm{kg}] \times 0.09 \mathrm{AH}^{0.5}
$$

referred from property data of Japan Cedar [10] )

Additionally, $Q_{v \max }$ is dependent on room temperature, however less than $5 \%$ difference is found between inflow vents estimated by room temperature and the above conventional equation in much of the experiment data. Therefore, the value estimated by the above equation is used as a standard.

The Y-axis indicates the combustion efficiency $(\eta)$, which is the net heat release rate $\left(Q_{o x}\right)$ measured with the furniture calorimeter standardized by the nominal supplied heat release rate $\left(Q_{\text {sup }}\right)$. This figure indicates that when $\Phi$ is $0.75, \eta$ starts to decrease. When $\Phi$ is 1.27 , $\eta$ decreases to the minimum point at about $75 \%$ to $82 \%$ of the nominal heat release rate of the supplied gas. Moreover, when the supplied fuel increases, $\eta$ tends to increase. There is an example wherein $\eta$ becomes $100 \%$. when $\Phi$ is 2.0 The following regression curves are obtained in these experiments.

$$
\eta=1-0.23 \exp \left(-5.32(\phi-1.27)^{2}\right)
$$

Figure 5(b) presents the same data but normalization of the $\mathrm{Y}$-axis is different from that in Fig. 5(a). The net heat release rate is normalized by the $Q_{v \max }$. This figure indicates that when the supplied fuel increases the net-heat release rate $Q_{o x}$ seems to converge to $Q_{v \max }$, and once $\Phi$ exceeds 1.27 , it can be observed that flames ejected to the outside intensify and

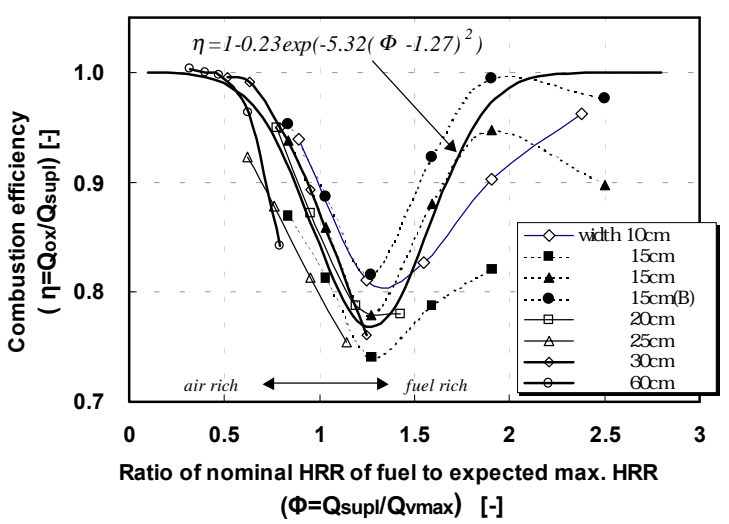

(a) $\mathrm{Q}_{\text {supl }} / \mathrm{Q}_{\text {vmax }}$ vs. combustion efficiency $(\eta)$

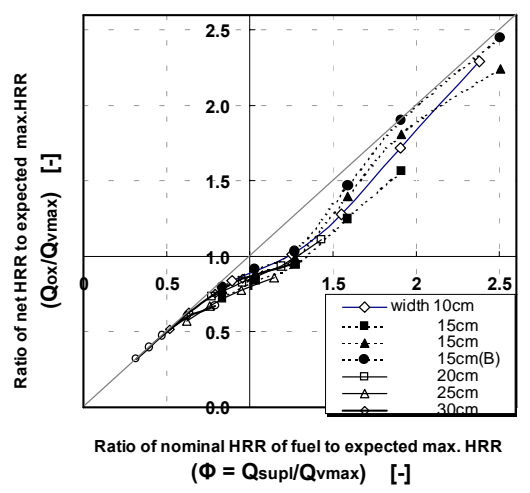

(b) $\mathrm{Q}_{\text {supl }} / \mathrm{Q}_{\text {vmax }}$ vs. $\mathrm{Q}_{\mathrm{ox}} / \mathrm{Q}_{\mathrm{vmax}}$

Fig. 5 - Combustion efficiency under various conditions of opening and heat supply: Fuel is propane gas. 


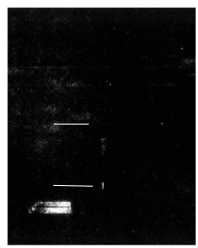

$\mathrm{Q}_{\text {supl }}=22 \mathrm{~kW}$

$(\Phi=0.87)$

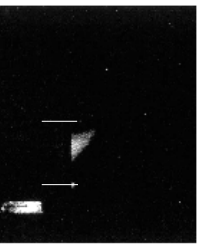

$32 \mathrm{~kW}$

(1.26)

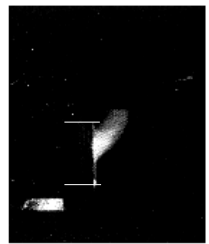

$40 \mathrm{~kW}$

(1.57)

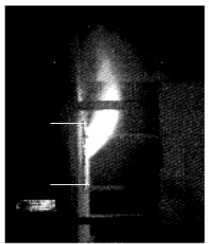

$49 \mathrm{~kW}$

(1.93)

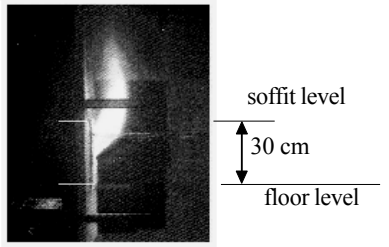

$61 \mathrm{~kW}$

(2.44)

(a) opening width $=10 \mathrm{~cm}$ : Qvmax $=25.4 \mathrm{~kW}$

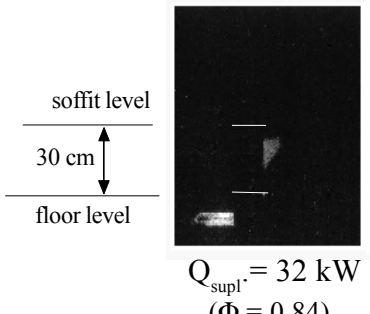

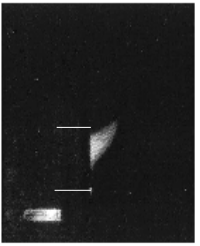

$40 \mathrm{~kW}$

(1.05)

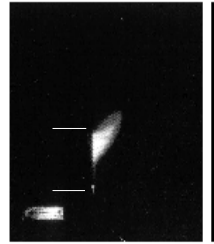

$49 \mathrm{~kW}$

(1.29)

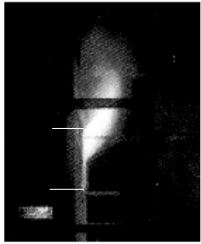

$61 \mathrm{~kW}$

(1.60)

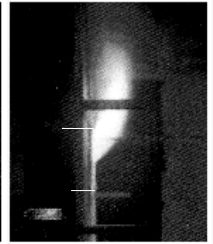

$73 \mathrm{~kW}$

(1.92)

(b) opening width $=15 \mathrm{~cm}: Q_{\text {vmax }}=38.1 \mathrm{~kW}$

Fig. 6 - Examples of side view of ejected flames: Fuel is propane gas. Pictures are multilayered VCR images during 60 seconds (total 1800 pictures) in quasi-steady state.

that luminance of the ejected flame increases. Then the combustion efficiency is improved as shown in Fig.6. It is presumed that unburnt gas is burning outside effectively, which is a typical case of the flame formation mechanism shown in Fig.1(b).

Combustion efficiency of in the cases of solid fuel

Three kinds of solid fuel listed in Tab. 1 were respectively burned in the compartment with a $30 \mathrm{~cm}$ wide by $30 \mathrm{~cm}$ high fixed opening . Figure 7 shows the time curve in net heat release rates of each solid fuel, i.e., $Q_{w t}$ estimated by mass loss rates, and room temperature at the center of the room $2 \mathrm{~cm}$ below the ceiling as a reference. And Fig.8 shows fire evolution process plotted by $Q_{w} / Q_{v \max }$ in the X-axis, which corresponds to the 'fuel to air' global equivalence ratio, and combustion efficiency $(\eta)$ in the $\mathrm{Y}$-axis. The lines and arrows indicate the time trend of the experimental plots. These figures indicate that characteristics of combustion development are changed by quantity of fuel load as well as material.

In Fig.7 (a) and Fig.8 (a), since the average heat of combustion $\left(\Delta H_{\text {wood }}=14.8 \mathrm{MJ} / \mathrm{kg}\right.$ derived from total heat output measured by furniture calorimeter) of the wood is used to estimate the net heat release rate $Q_{w t}$, it is necessary to note that $Q_{w t}$ is overestimated, i.e., $\eta$ is underestimated, in the beginning when a large amount of moisture is evaporated. In the case of wood cribs No.1, there are two distinguished stages: one is the first plateau leveled at about $80 \mathrm{~kW}$ between 260 and 350 seconds after ignition and the other is a developing combustion stage after the period. When the amount of wood cribs is smaller in case No.2, this first stage is not observed.

The distinctive difference of the evolution process can bee seen in Fig. 8 (a). When a small amount of wood cribs is used in case No.2, the heat release rate approaches $Q_{\text {vmax }}$ and $\eta$ approaches $100 \%$ as time elapses. On the other hand, when a large amount of fuel is used, as in case No.1, the combustion process is the same as that of No.2 at the beginning, however 


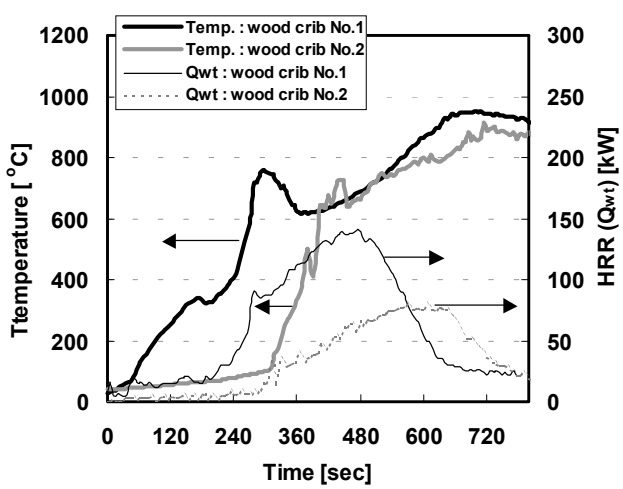

(a) Wood cribs

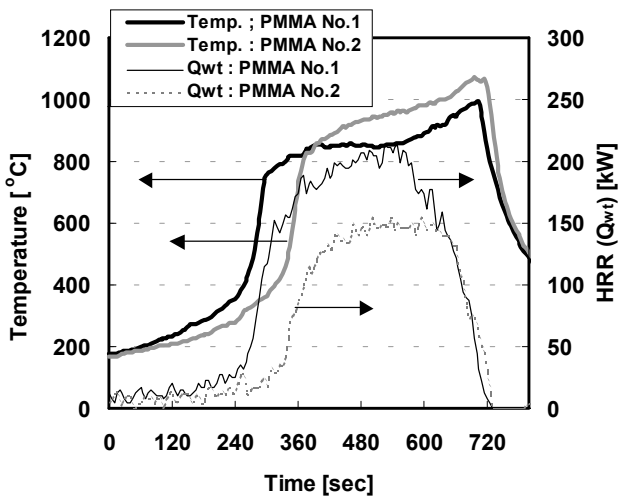

(b) PMMA ${ }^{a}$.

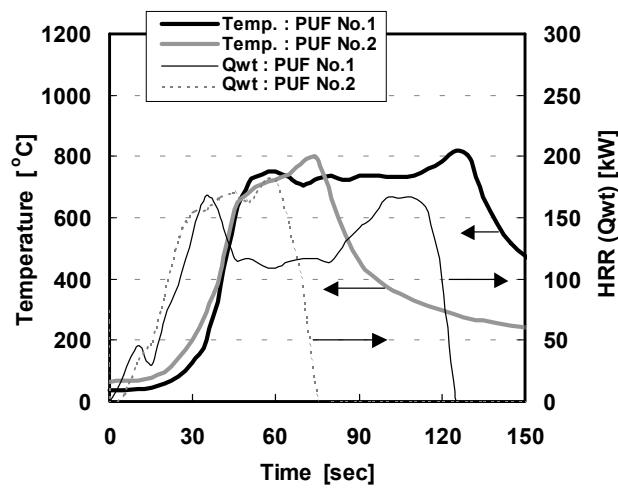

(c) Polyurethane flexible foam

Fig. 7 - Time curve of room temperature and heat release rate in the case of solid fuels : HRR is estimated by mass loss rate.Room temperature is measured at the center of th room and $2 \mathrm{~cm}$ below the ceiling.

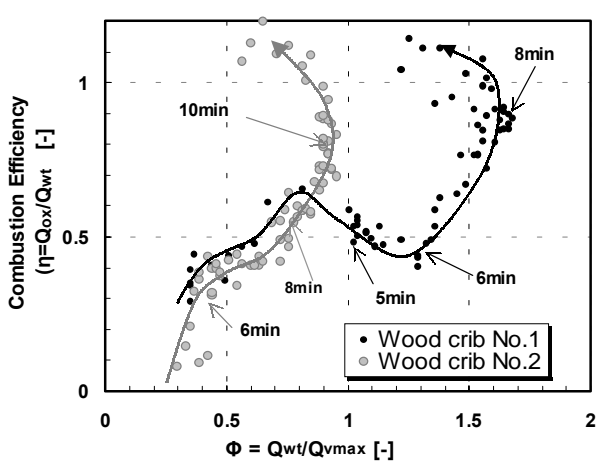

(a) Wood cribs

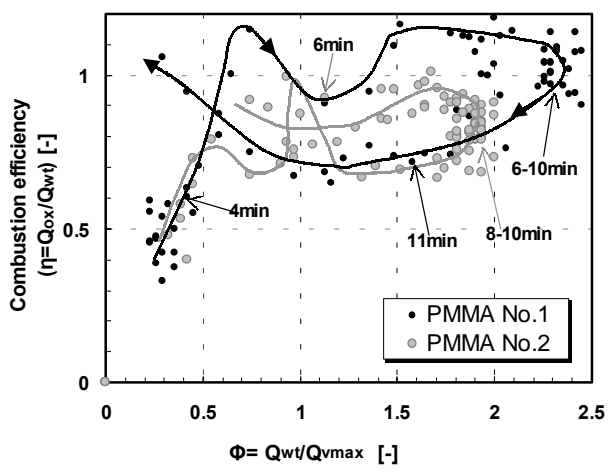

(b) PMMA

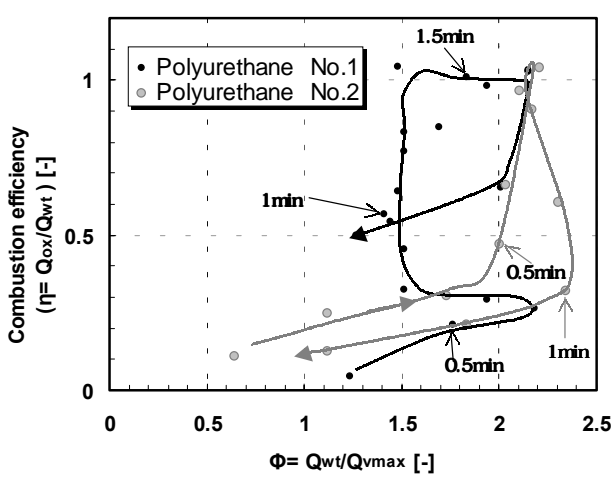

(c) Polyurethane flexible foam

Fig. 8 - Combustion efficiency vs. 'fuel to air' global equivalence ratios $(\Phi)$

a. Initial fire spreading of PMMA is relatively slow. Time indicated in fig. (b) is offset from the time lapse from ignition; $900 \mathrm{sec}$. in case No.1 and $1350 \mathrm{sec}$. in case No.2 respectively. 
it changes as the mass loss rate increases. After combustion efficiency declines once at the point of $Q_{w} / Q_{v \max }$ $\approx 1.3$, it rises toward $100 \%$ again. This burning development coincides with that of gas fuel.

In the case of PMMA ignited with a small ignition source, initial fire spread is relatively slow. Time indicated in Fig.7 (b) and Fig.8 (b) is offset from time lapse from ignition: i.e., $900 \mathrm{sec}$. in case No. 1 and $1350 \mathrm{sec}$. in case No. 2 respectively. However the development of the combustion becomes relatively rapid once the reference room temperature reaches almost $400{ }^{\circ} \mathrm{C}$, and the combustion efficiency approaches $100 \%$. Even in this case, the burning efficiency drops once between

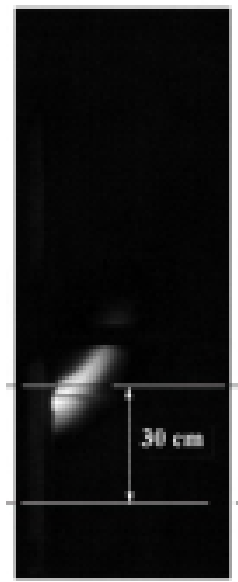

(a) $5 \mathrm{~min}$.

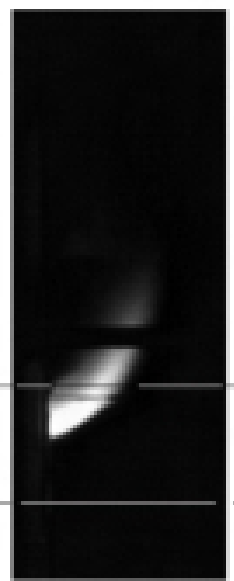

(b) $6 \mathrm{~min}$.

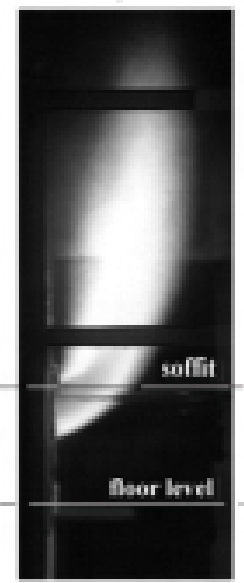

(c) $8 \mathrm{~min}$.

Fig. 9 - Ejected flames in the case of wood cribs fire: Figures are multi-layered VCR pictures during 10 seconds (total 300 pictures) after the indicated time lapse from ignition. 1.0 and 1.5 of $\Phi$, and beyond that point the efficiency improves again. The longer ejected flames are observed and much of the fuel burns outside in the case of larger amount fuel, and this seems to make room temperature lower than that in the case of smaller one.

In the case of polyurethane flexible foam shown in Fig.7(c) and Fig.8(c), the total fuel load is less than others, however it burns very rapidly in a short period. In such a case especially for smaller amount of fuel, room temperature does not become high to make enough air flow into the room. The combustion in case No.2 is almost the same as open fires and the analysis referred to $\Phi$ is not appropriate. In case No.1 of larger amount of fuel, rapid burning consumes air inside the compartment, and the burning rate drops once. Then it increases again and the combustion efficiency rises up to $100 \%$ while $\Phi$ is 1.5 as it is observed in the case of wood crib No.1. Further analysis for understanding the rapid burning process is future task, because the present experimentation has a limit to follow the rapidfire growth.

The important information in these figures is that the maximum heat release rates become 1.5 to 2.5 times higher than the suppositional maximum value of heat release rate $\left(Q_{v \max }\right)$, which is definitely different from the past models of ejected flames. However, it is not unusual phenomena. Fleischmann [11] reported that the global equivalence ratio is 1.7 in a wide range and it reaches 3 when the opening factor is in a specific low value. Even the fuelrich condition is in the range beyond 1.3 of $\Phi$, the ejected flames stretch long to the outside and the luminance of the flames increases with less smoke production as shown in Fig.9. And combustion efficiency reaches $100 \%$. Similar phenomena of rapid flame development under fuel-rich conditions were shown by Bøhm [8]. Whether this type of flame ejection is a peculiar phenomenon that can be seen in a space of smaller size like in this experiment or not should be examined further. Also, as Hasemi [4] pointed out, smaller scale compartments tend to give a higher burning rate than normal ventilation controlled fires as many full-scale experiments indicated. This scale effect is one of the future tasks to be examined. 


\section{CONCLUSIONS}

Prior to developing an ejected flame model, the burning efficiency of fuel in fully developed fire compartments, which seems to be necessary to comprehend the formation mechanism, is measured in the experiment using a furniture calorimeter and the maximum heat release rate under ventilation control is measured. The major results are as follows:

1) In the experiment with propane gas in a quasi-steady state, when the 'fuel to air' global equivalence ratio $\left(\Phi=Q_{\text {supl }} / Q_{\text {vmax }}\right)$ is 0.75 , the combustion efficiency begins to decline. When $\Phi$ is 1.27 , the combustion efficiency decreases by $23 \%$. Moreover, when a larger amount of gas is supplied, external ejected flames develop and the combustion efficiency increases again.

2) In the case of the wooden cribs fire, it is observed that when the fuel load is relatively small, the mechanism to control burning by ventilation operates. Once the burning rates exceed the equilibrium point, ejected flames develop and the combustion efficiency improves.

3)When solid fuel burns in the compartment, it is observed that the maximum heat release rate of wooden cribs becomes 1.5 as large as the suppositional maximum heat release rate controlled by ventilation $\left(Q_{v \max }\right)$ and that the burning rate of plastic material becomes more than double $Q_{v \max }$. Both cases have the similar tendency that the combustion efficiency finally approaches $100 \%$.

\section{REFFERENCES}

[1] Suzuki, T., Sekizawa, A., Yamada, T., Yanai, E., Satoh, H., Kurioka, H. and Kimura, Y., "An Experimental Study of ejected Flames of High Rise Buildings - Effects of Depth of Balcony on Ejected Flame- ", Proceedings of the Fourth Asia-Oceania Symposium on Fire Science and Technology", Asia-Oceania Association for Fire Science and Technology, Tokyo, JAPAN, 2000, pp.363-373

[2] Thomas,P.H. and Law, M., "The Projection of Flames from Burning Buildings on Fire", Fire Prevention Science and Technology No.10: 19-26 (1974)

[3] Jansson, R. and Onnermark, B., "Flame Heights Outside Windows", National Defense Research Inst., Stockholm, Sweden FOA Report, C20445-AC, 1982

[4] Hasemi, Y. and Izumu, J., "Leading Mechanism and General Correlation of Flames from an Opening of Fire Enclosure“, Summaries of Technical Papers of Annual Meeting Architectural Inst. of Japan, Fire safety section, (in Japanese) 1988, pp.745-746

[5] Hägglund, B., Jansson, R. and Onnermark, B., "Fire Development in Residential Rooms after Ignition from Nuclear Explosions", National Defense Research Inst., Stockholm, Sweden FOA Report, C2016-D6(A3), 1974

[6] Sugawa, O. and Takahashi, W., "Flow Behavior of Ejected Fire Flame/Plume from an Opening Effected by External Side Wind", Fire Safety Science --Proceedings of the Fifth International Symposium on Fire Safety Science, International Association of Fire Safety Science, Melbourne, Australia, 1997, pp.249-260

[7] Takanashi, K., Suzuki,T. , Sekizawa, A., Yamada, T., Yanai, E., Satoh, H., Kurioka, H. and Kimura, Y., "Flame Configuration derived from Video Camera Picture - An Experimental Study of Ejected Flames of a High-rise Building Part II- “, Report of National Research Institute of Fire and Disaster No.91, Mitaka, JAPAN, 2001, pp.48-58

[8] Bøhm,B. and Rasmussen, B.M., "The Development of a Small-scale Fire Compartment 
in order to Determine Thermal Exposure Inside and Outside Buildings", Fire Safety Journal, 12 : 103-108 (1987)

[9] Drysdale,D., An introduction to Fire Dynamics( $\left.2^{\text {nd }} e d ..\right)$, John Wiley and Sons, Chichester, 1999, p.19 and p.331

[10] Suzuki, H. "Fire Safety Performance of Material and Products". Fire Handbook Kasai Binran- ( $3^{r d}$ ed.) ,(in Japanese), Japan Association for Fire Science and Engineering, 1997, p.803

[11] Fleischemann, C.N. and Parkes, A.R.,"Effects of Ventilation on the Compartment en hanced Mass Loss Rate", Fire Safety Science -- Proceedings of the Fifth International Symposium on Fire Safety Science, International Association of Fire Safety Science, Melbourne, Australia, 1997, p.p.415-426 